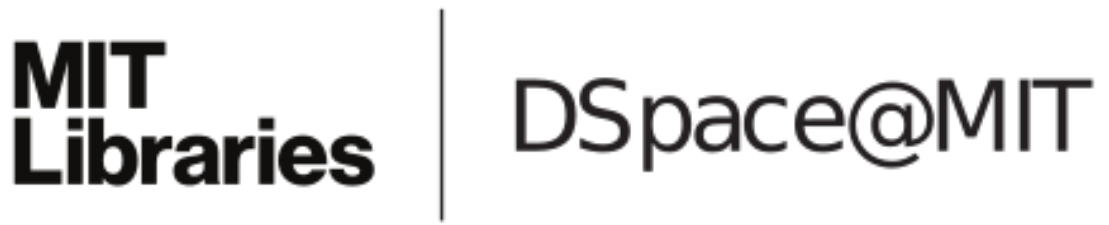

\author{
MIT Open Access Articles
}

Management Levers for Product Platforms

The MIT Faculty has made this article openly available. Please share how this access benefits you. Your story matters.

Citation: Cameron, Bruce G., Edward F. Crawley, Jakub Kwapisz, and Alicia McNeill.

"Management Levers for Product Platforms." Engineering Management Journal 29, no. 3 (July 3 , 2017): 128-139.

As Published: http://dx.doi.org/10.1080/10429247.2017.1323569

Publisher: Informa UK Limited

Persistent URL: http://hdl.handle.net/1721.1/114491

Version: Author's final manuscript: final author's manuscript post peer review, without publisher's formatting or copy editing

Terms of use: Creative Commons Attribution-Noncommercial-Share Alike 


\title{
Management levers for product platforms
}

\section{Bruce G. Cameron, Edward F. Crawley, Jakub Kwapisz, Alicia McNeill}

\author{
Dr. Bruce G. Cameron (Corresponding Author) \\ Partner, Technology Strategy Partners, and Director, System Architecture Lab, MIT \\ 678 Massachusetts Ave, Cambridge MA 02139 \\ bruce@t-s-partners.com \\ Dr. Edward F. Crawley \\ Professor of Aeronautics and Astronautics, MIT \\ 77 Massachusetts Ave., 33-413, Cambridge MA 02139 \\ crawley@mit.edu \\ Dr. Jakub Kwapisz \\ Global Product Manager, Autoneum \\ 77 Massachusetts Ave., 33-409, Cambridge MA 02139 \\ jjkwapisz@gmail.com \\ Alicia McNeill \\ Consultant, Technology Strategy Partners \\ 678 Massachusetts Ave, Cambridge MA 02139 \\ Alicia.McNeill@t-s-partners.com
}

\begin{abstract}
Platforming has become an important means of cost-sharing among industrial products. However, many firms face systemic downward pressure on commonality, with the result that many platforms realize less commonality than intended. Past research has hypothesized that divergence is the result of conflicting tensions between product customization / optimization and cost control. This article investigates the control and incentive levers available to platform managers to shape the behavior of the organization when divergence opportunities arise. Management levers are drawn from a series of 12 industrial case studies, stemming from investigations of the causes of divergences. These management levers are categorized as technical levers, financial levers, and organizational levers. This paper illustrates each of the management levers with examples from the case studies.

\section{Introduction}

Platforming, or the intentional sharing of parts and processes across products, has become increasingly used as a strategy to deliver product variety. Platforming enables firms to deliver similar products to multiple markets and multiple vertical segments (Meyer and Lehnerd, 1997), to dynamically enter niche markets more quickly as a result of identified needs (K. Ulrich, Randall, Fisher, and Reibstein, 1998), and can be coupled with strategies of mass customization (Fisher, Jain, and MacDuffie, 1995; Alptekinoglu and Corbett, 2008).
\end{abstract}


One of the key advantages of platforming is cost sharing across industrial products. Examples include the Joint Strike Fighter program (variants for the Air Force, Marines, and Navy), Black and Decker's electric hand tools (Meyer and Lehnerd, 1997), and Volkswagen's A platform (including VW Jetta, Audi TT, and Seat Toledo) (Bremner, 1999). This platforming strategy has been used to enable firms to deliver more product variety to the marketplace on a smaller cost base.

However, concerns have arisen around the complexity of product offerings, asking whether customers actually require the full span of variety offered (K. Ulrich et al., 1998), and whether the benefits to customers are merited by the complexity incurred (MacDuffie, Sethuraman and Fisher, 1996). These benefits are difficult to evaluate and usually involve assessment of more complex and holistic problem space, including organizational, economical, and policy dimensions that occur in ambiguous and uncertain conditions (Keating, Padilla and Adams, 2008).

Recent work has raised another challenge to product variety specific to platforms. Research indicates that products built sequentially often exhibit divergence from the platform (Boas, Cameron, \& Crawley, 2013). Divergence is defined as lower commonality among product variants than targets set during product conception. This divergence behavior arises when tradeoffs need to be made between product customization, optimization and cost control. This has potentially profound implications for the success of platform strategies - if firms invest in platforming to realize cost savings, or create significant complexity to realize variety, but fail to achieve high commonality levels, they may also fail to obtain large benefits .

In this paper, we investigate the potential management levers available to manage divergence, focused on platforms seeking to achieve cost-savings through intentional commonality (as opposed to reactive reuse). We review the existing literature on platform success, and discuss conflicting indications. We examine recurring actions across a series of case studies to examine how practitioners actively manage issues, rather than proscriptively approaching the topic by analytic methodologies. Our research is necessarily exploratory, in that few findings on divergence to date. To these ends, case studies provide a research method enabling close examination of the phenomena in context, particularly where the boundary between phenomena and context is uncertain (Yin, 1981; Eisenhardt, 1989).

\section{Background}

This background section conducts a review of the benefits of commonality that could be impacted by divergence, and then examines the available knowledge in the literature relevant to divergence and commonality change. A detailed review of literature on investment returns on platform investments is then conducted. We begin with the benefits to ensure that when we later review management levers, the objective of the platform strategy remains in the center of focus.

\section{What are the benefits of commonality?}

Meyer (1997) cites several potential benefits of commonality including enabling future rapid product introduction, increase model introduction rate, decreased development cost, economies of scale in manufacturing, and faster introduction of new technology into existing product lines. Meyer (1997) also notes possible penalties including commonality risk (a failed common component has a broader footprint) and capability penalty (unwanted cost of higher capability common components in lower-priced variants). 
Robertson and Ulrich (1998) frame platform development in the context of two primary activities: similarity analysis and differentiation analysis. They assert that these are mutually exclusive through their impact on revenue and cost. In addition to the benefits and penalties listed in Meyer (1997), they include shared investment in equipment and reduced complexity costs associated with materials and logistics as additional benefits of commonality. Their model of complexity cost implicitly asserts that the overhead of owning and managing common parts is less than the complexity cost of many parts. Robertson et al. (1998) explicitly recognize increased complexity cost of platform development. Fisher, Ramdas, and Ulrich (1999) present a trade-off between costs and benefits of commonality using a mathematical model, finding broader performance spreads and larger production volumes which lead to larger numbers of component types, but they omit economies of scale.

Krishnan, Bass and Jain (1999) and Krishnan and Gupta (2001) construct profitability models of commonality penalties and benefits. They capture "the trade between economies of scale and increased costs associated with excess capability". The literature on lean product development has asserted that benefits of lean (such as reduced waste) could be partially achieved by reuse and modular components (Hoppmann, Rebentisch, Dombrowski and Thimo Zahn, 2011). Ramdas and Randall (2008) studied component failure and their reliability from the perspective of commonality. Although their case study was conducted in one automotive company and on one specific part, conclusions of the study are interesting. One of their findings is that higher component reliability is connected to greater know-how about a component, and thus might be connected to reuse of that component. On the other hand, they find that components designed for a single product have higher reliability.

A number of benefits are captured within normative cost models in the Engineering Design literature on commonality. Simpson (2005) reviews 32 papers in the Engineering Design literature, of which only 14 considered cost as a factor. These models often include a subset of benefits convenient for analytic tractability. For example, Fujita (2002) compares development cost against production cost using the simplifying assumption that more commonality implies lower development cost. Cameron and Crawley (2013) summarized a list of commonality benefits and costs, which is based on an in-depth literature study. The authors demonstrated that benefits are spread through the product lifecycle. The variety of benefits, spanning strategy, supply chain, operations, etc., is the likely cause that the benefits of commonality have not previously been aggregated in one place. Some benefits relate to fixed cost investments which are leveraged for each new product (such as shared development), while other benefits relate to recurring cost reductions (such as learning curves). Johnson and Kirchain (2010) compared different matrices evaluating commonality cost benefits concluding that the majority of savings came from component sharing in the development and assembly cost categories, not in fabrication.

\section{Divergence -Decreases in Commonality}

Boas et al. (2013) provides the first synthesized view of decreases in commonality. Boas et al. (2013) finds that divergence is driven by an imbalance of current over future interests in the platform. The same authors identify both beneficial and detrimental effects of this behavior. However, earlier indications of challenges to commonality exist in the literature. "Muffatto and Panizzolo (1996) highlights the engineering culture at Honda as one of the first problems that had to be faced when trying to reach the desired carry-over degree of $50 \%$ (previous degree 12\%) for the Honda Accord 1993 model. [...] The mental attitudes of the engineers at Honda 
were based upon the pride of always developing unique technical solutions for every model" (Nobelius and Sundgren, 2002). Muffatto's work contains early signals of what Boas et al. (2013) described as "intentional pursuit of uniqueness" as a cause of divergence. The drivers of this supposedly irrational behavior have not yet been examined.

Nobelius et al. (2002) offers one of the few examples in the literature of causation of divergence. "The responsible engineer was probably not aware of the downstream consequences of introducing new dimensions. Moreover, later another design approach, based on using shorter screws instead of manipulating the distance, solved the crashworthiness problem, but at that time the tooling investments were already made". Nobelius et al. (2002) emphasizes lack of attention (which they title "strategic intent") as the central cause of this divergence - a failure to request necessary information. This is different from the questions of information availability. Nobelius et al. (2002) ties this lack of attention to both organizational structure (the extent to which the parts sharing strategy is communicated across functional groups) and design process linearity (too many constraints are already fixed which makes parts sharing design difficult). While the theory built from this single case is small relative to the magnitude of existing research streams on commonality, it is sufficient to suggest that organizational structure is a potential consideration in examining the incentives for divergence. Technology management techniques offer promise in improving communication between different company units (Phaal and Palmer, 2010; Costa, Rozenfeld, Amaral, Marcacinit and Rezende, 2013).

Boas et al. (2013) finds evidence for divergence in all 7 cases studied, although to varying degrees - a military aircraft case sees commonality fall by half, in comparison with smaller changes to commonality in a semiconductor capital equipment case. Boas et al. (2013) identifies six drivers of divergence:

- Market change - Common solution no longer meets new market needs

- Learning occurs - Commonality premium is revealed to be too expensive

- New technologies arise - Interfaces to old technologies are superseded

- Lifecycle offsets - Products are designed serially, leading to imbalances of influence on platform definition (an extension of the work on lifecycle mismatch by Bradley and Guerrero (2008); Bradley and Cooper (2008))

- Failure to consider lifecycle benefits - Decisions made on a near-term horizon

- Intentional pursuit of uniqueness - Creating unique parts when capable parts are available

The first four drivers can result in both beneficial and detrimental effects, but the last two drivers have solely negative effects. What this work begins to uncover is the possible reasoning for divergence decisions, but it does not uncover how to prevent divergence from occurring. Additionally, the explanatory power of the theory is limited given relatively few variables are identified.

\section{How does platforming perform as a cost-saving strategy?}

Relatively little statistical research is available on the performance of commonality as a cost savings strategy. While the management science literature includes several profitability models (Krishnan \& Gupta, 2001; Fisher et al., 1999), and in select cases, the models are populated with accurate cost data (Johnson et al., 2010), these models are not designed to generalize about the profitability of platforms. Rather, they are normative tools, intended to facilitate decision making on a given platform. A number of individual data points are available 
from one-off cases in terms of savings or benefits, but these are rarely compared with the unique cost given the challenges of the counter-factual. For example, Boas et al. (2013) notes that development costs for subsequent variants were reduced (15\% of lead variant cost for Company E, $50 \%$ of lead variant cost for Company F). The challenge in comparing these individual data points is that cost savings is not the sole benefit provided by commonality strategies, and thus a sample might include non-homogenous data - for example, some projects will have foregone cost savings in lieu of revenue gains, whereas others will have pursued only cost savings.

Tatikonda (1999) conducts one of the few statistical studies on platforms. He aims to understand the difference between lead variant development and derivative variant development, which he titles "platform projects" and "derivative projects". Tatikonda (1999) rejects the hypothesis that lead variants are less successful than derivative variants, based on a survey of 108 variants. The measure of success is 'achieving project objectives' and 'customer satisfaction,' not return on investment (ROI) specifically. Additionally, Tatikonda's (1999) scale for identification of lead and derivative variants conflates the ideas of commonality with the ideas of project scale - in effect assuming that derivative variants are small projects. As variants are the unit of analysis, Tatikonda (1999) does not render results on platforms as a whole. The study does not engage in a discussion of benefits and penalties, other than to note that "contingency planning" is correlated with success for both lead and derivative variants.

The only study identified which made mention of potential negative consequences of platforming was Hauser (2001), where profitability was found to be negatively correlated with platform reuse for $n=16$ products within an office-supply firm. The product variety literature contains empirical studies of product families, such as Ulrich et al. (1998). Ramdas (2003) found that "for low-quality segments, brand price-premium is significantly positively correlated with the quality of the lowest quality model in the product line." It is possible that product families are not necessarily examples of commonality strategies, as it is feasible to produce a product line family with escalating performance and price without employing commonality.

Comparisons of strategy effectiveness in the component standardization literature are more common (Sered and Reich, 2006; Jose and Tollenaere, 2005), perhaps because the cost effects can more linearly be separated from the revenue effects of platforming. Labro (2004) describes three broad research streams on component commonality cost:

1. Effect of component commonality on inventory levels. Baker, Magazine and Nuttle (1986) initially identified the potential benefit, driven by risk pooling, resulting in reduced safety stock levels (Mirchandani and Mishra, 2002).

2. Other internal firm costs influenced by component commonality.

3. Influence of market effects - relaxation of the assumption that component commonality is independent of revenue. (Kim and Chhajed, 2000; Desai, Kekre, Radhakrishnan and Srinivasan, 2001; Jans, Degraeve and Schepens, 2008).

While statistical studies across firms were not evidenced in the literature search, individual data points on the strategy are plentiful. For example, in the late 90's Nissan was expecting 3\% savings of its cost by a $30 \%$ decrease in the number of parts it was using in the ten years (Kim and Chhajed, 2000).

Jans et al. (2008) frames a component commonality decision in terms of a net present value (NPV) investment problem involving both revenue and cost, but develops a model dominantly focused on revenue gains as 'return', rather than downstream cost savings. Lifecycle offsets are not considered, which raises questions about generalizability to programs that do not proceed with all variants developed in parallel. Desai et al. (2001) notes that commonality can 
save later development costs, as well as downstream manufacturing costs, but then states too broadly "manufacturing costs always decline with the use of commonality," and chooses not to incorporate the time value of money in the model they produce.

Ward et al. (2010) takes a sophisticated operations research approach to the complexity vs. variety trade in product families at Hewlett Packard. They propose a ROI hurdle for new variant introduction, defined as the incremental margin less the variable platform costs over the fixed platform costs. This measure does not discount costs over time, and does not apply to a product family as a whole, but does conceptually use the term investment.

Kogut and Kulatilaka (1999) offers the closest match to the commonality investment concept, but is truly on the perimeter of the commonality literature, on the border with much broader management topics of "core competencies." A very holistic discussion is offered - the paper is not data focused. The term "platform" is used very loosely, covering physical assets from which derivate variants can be constructed as well as firm capabilities in design and management. The detailed trades of commonality (performance against unit cost, capability penalty, etc.) are not covered at all. The paper emphasizes platforms as real options on future market needs, and suggests that valuation of near term benefits of commonality to the exception of long-term benefits will lead to under investment in commonality. Kogut and Kulatilaka (1999) also discuss devaluation of investment returns as a result of competitor actions (a key link between revenue and cost sides of commonality that is infrequently discussed), but focuses discussion on the lost revenue rather than on the write down of unamortized platform costs.

None of the papers reviewed in the broader commonality literature identified issues around allocation of commonality investment to variants or differential return targets for lead variants. The word "investment" is frequently used to describe the research and development (R\&D) costs associated with common development programs, but the use of discount rates was sporadic and judged unimportant while the use of payback period comparison, risk-return analysis, and other traditional investment evaluation methods was not evidenced. No papers in the literature offered data to facilitate comparisons of the magnitude of commonality investment.

Across these three questions (what are the benefits, what is divergence, how has commonality performed as a strategy), we worked from a detail review of the benefits of commonality (the objective of the strategy), to a review of the literature on divergence (new data about execution of the strategy), to a review of the literature on platform investments (how has the strategy performed?). We surface several potential management levers, such as the failure to request the necessary information on commonality (Nobelius 2002), and the potential for organizational structure to influence incentives for commonality. Additionally, the review of benefits brings a financial dimension to a problem that is often treated in either organizational or technical-only domains, which helps motivate the need for a set of financial levers in the management levers section. While there is substantial literature on commonality, and several management levers are identified, there is a gap in terms of cataloging management actions available. Many individual contributions propose a single lever, such as Ward's (2010) for an ROI hurdle for new variant introduction. More importantly, there is a gap in the literature in identifying how to manage in the presence of divergence. The causes of divergence have begun to be studied, but the literature has not yet addressed which actions can be taken to prevent it, or better yet, when should it be prevented and when should it be encouraged?

\section{Research Methodology}


Building on the causes of divergence from Boas (2013), the intent of this research was to investigate the factors that shape divergence outcomes, and more broadly, to investigate the management levers employed in platforms. A case study approach was chosen, based on Yin's (1981) concept that case studies are appropriate when "the boundary between phenomenon and context is not clear," given the multitude of other sources of cost and the complexity of platform development programs. Although surveys have been successfully used in this practice area (Cusumano and Nobeoka, 1998; Landaeta, 2008), surveys by their nature focus on known concepts and mechanisms, and trade larger- $\mathrm{N}$ responses for programmatic detail. It was not expected that consensus had already been constructed within the organization relating to this hypothesis; therefore, survey methods aimed at demonstrating a majority view are not of interest.

The research design for the case studies followed a mixed-methods approach (Greene, Caracelli, and Graham, 1989; Burgess, McKee and Kidd, 2005; Creswell, 2013), where both qualitative data from interviews and quantitative raw data was collected from project studies. Interviews were used to capture the operational complexity and prioritize the benefits of commonality. Given the complex causal relationships which were highlighted in the literature search, as well as the known multi-period feedback, the case study approach was believed to best enable the exploratory and descriptive nature of the research problem (Ngai et al., 2007; Rungtusanatham \& Salvador, 2008; Triantis, 2000; Nepal, Yadav, and Solanki, 2011).

\section{Case Selection}

A series of scoping interviews were used to test research concepts, interview questions, and to focus the research program. These scoping interviews were conducted with 23 firms. The target firms for generalization were similar programs in different companies and industries, where 'similar' is defined as executing plans for product platforms that contain lifecycle offsets. These scoping interviews were drawn from a wide range of industries (aerospace, high tech, transport, white goods, industrial goods, consumer goods, automotive, mining) in order to capture a spectrum of benefits and to uncover as many factors that influence divergence decisions as possible. Each benefit cannot appear in every platform, therefore this approach enabled a broader conceptual footprint.

Based on the scoping interviews, we down-selected to 12 firms in order to examine the management levers employed in greater detail. The platforms selected for the 12 cases were all focused on examples of intentional commonality (excluding passive reuse), and where the primary purpose of commonality was cost-saving. The 12 cases were primarily capital-intensive manufacturing, long lifecycle, slow clockspeed industries (Fine, 1998). This context was chosen based on evidence of long-term planning for commonality (due to slow clockspeeds), and concrete representations of commonality levels by parts (consistent with capital intensive products). Multiple-case research uses different cases to progressively refine and validate theory addressing a specific question. The list of cases is provided below. More detail on each case can be found in (Boas et al., 2013, Cameron and Crawley, 2012, Cameron, 2011).

Exhibit 1. List of case studies, defined by the industry in which they were conducted 


\begin{tabular}{|r|l|}
\hline Case ID & Case Name \\
\hline 1 & Vehicle Manufacturer \\
\hline 2 & Heavy Equipment \\
\hline 3 & Rail Equipment \\
\hline 4 & Automotive Manufacturer 1 \\
\hline 5 & Automotive Manufacturer 2 \\
\hline 6 & Helicopter Manufacturer \\
\hline 7 & Lockheed Martin's Joint Strike Fighter \\
\hline 8 & Business Aircraft \\
\hline 9 & Commercial Aircraft \\
\hline 10 & Commecial Satellites \\
\hline 11 & Printing Presses \\
\hline 12 & Semiconductor Capital Equipment \\
\hline
\end{tabular}

\section{Data Collection}

Interviews were used to collect qualitative data, guide quantitative data collection, and support conclusions. Interviews were conducted in a semi-structured format based on a 4-page questionnaire using structure and reasoning presented in variety of studies (Harris and Brown, 2010, Creswell, 2013, Sutton, 1997). A subset of questions that guided interviews were the following:

- Was a commonality metric tracked during the project?

- How did commonality change over time in your product families?

- What do you believe are the causes of this change?

- How do management actions influence commonality and potential divergence?

- What are the benefits and penalties of commonality?

- Please list the major commonality decisions / events.

- For each commonality decision / event, what was the decision horizon considered?

- Are the investment criteria for a lead variant different from subsequent variants (ROI, payback period, capitalization)?

Interview lists were constructed with the company sponsor based on achieving exposure to the relevant systems and functions pertaining to the platform in question. Saturation was gauged based on exposure to all functional subsystem groups.

In total, 268 documented hours of interviews were conducted, ranging up to 44 interviewees per case, the vast majority of which were one-on-one interviews lasting one hour. Additionally, 101 archival documents were reviewed, including design review presentations, project investment submissions, and strategy documentation.

\section{Analysis Methods}

A commonality timeline was constructed for each case, from a combination of available commonality measures and commonality decisions elicited during interviews. A form of this timeline was reviewed with interviewees for validation.

Interview data on benefits was examined against quantitative measures with a focus on plausible timeline causation. Rival hypotheses for benefit change were sourced from interview data, categorized by benefit, and examined against interview data as well as corroborating quantitative data. Where available, detailed analysis of correlation was conducted on time series of commonality data and benefit change. Summaries of benefit impacts were presented to interviewees in an effort to search for additional rival hypotheses. 
Program narratives were created to describe the context in which commonality decisions were made. These narratives catalogued a fixed set of hypothesized variables (such as R\&D allocation policy), as well as emergent patterns from interviews (such as new part introduction costs and processes). These narratives were presented to the interviewees for feedback, but editorial authority resided entirely with the research team to prevent local biases.

A review of the interviews, archival documents and narratives was combined with a review of the literature to develop a potential list of management levers for product platforms. These levers represented common actions taken by or suggested by managers in the case studies, with a view to changing the program's behavior and outcomes regarding commonality decision making, and will be explored in the sections below.

\section{Management levers for product platforms}

We define management levers as actions the platform manager can take to shape the behaviors and outcomes of the program. These levers are specifically focused on platforms, therefore we exclude actions that are generically applicable to non-platform projects, such as adding additional headcount to a project behind schedule (Engwall and Jerbrant, 2003). Note that these levers are not focused on eliminating divergence - they are intended to help resolve conflicting tensions between product customization / optimization and cost control, where the objective function is the overall financial profitability of the platform.

The analysis conducted on the cases revealed that many of the proposed management levers have an existing presence in the literature, although none of the literature reviewed collected them together, or examined their collective potential as relates specifically to management of commonality.

With regards to literature focused on management of divergence, Boas et al. (2013) identify six drivers of divergence, only three of which are directly under the control of the platform manager: lifecycle offsets, failure to consider lifecycle benefits, and intentional pursuit of uniqueness.

Boas had identified failure to consider lifecycle benefit, which is expanded here as a composite of the scope of investment evaluation (what derivatives are in scope), the choice of development cost allocation (what derivatives are in scope and which contribute financially), design review participants (who authorizes technically), and the variant impact matrix (who is consulted for changes). Second, Boas had identified intentional pursuit of uniqueness as a behavior, which is impacted by management oversight (architecture control strategy as a lever), metrics on which engineers are judged (commonality metrics as a lever), ease of reuse (reuse databases as a lever), among others. Finally, Boas identified lifecycle offsets as a lever, which is explicitly captured as variant ordering by volume, to the extent that this is controllable inside the firm and not dictated by competitors or exogenous conditions in the market.

We differentiate between control and incentive levers. Management control systems are the information based practices which are used by managers in order to retain or modify inside company norms (Simons, 2013). Some authors argue that control is not enough, and knowledge management should be facilitated by firm culture and incentives (Alavi and Leidner, 2001, Khosrowpour, 1996). Even from a risk management perspective it is important to create a solid base of control; however, incentives - the soft side of management - can often be more important (Lam, 2014). 
Exhibit 2 presents the management levers. These management levers should not be interpreted as best practice, i.e. all of them should be present on each platform. The mix of levers shapes the control and incentive structures on a platform - use of new levers should reflect perceived imbalances in the degree of commonality vs. differentiation present.

Exhibit 2. Management levers categorized into financial, technical, and organizational groups

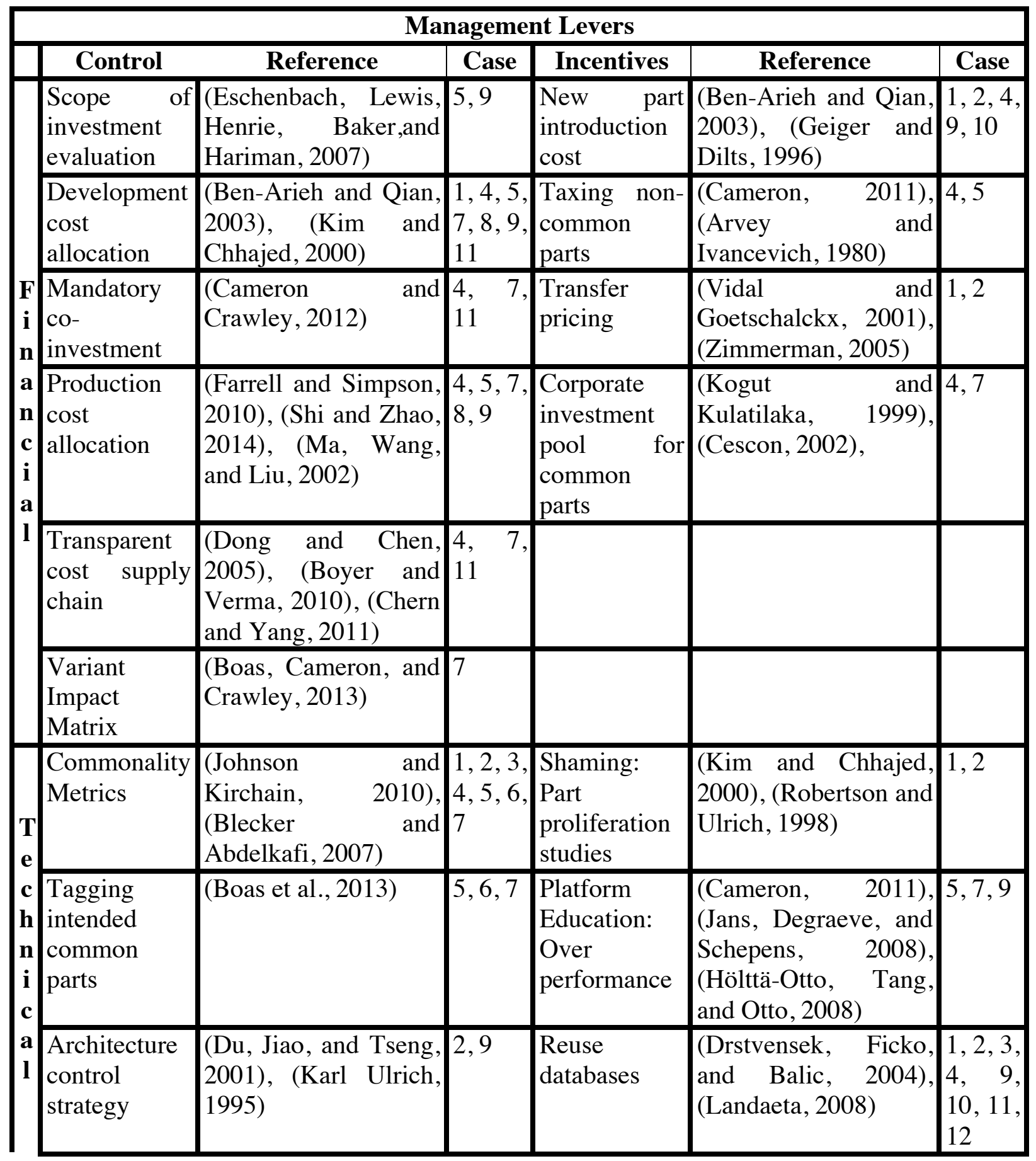




\begin{tabular}{|c|c|c|c|c|c|c|}
\hline & \begin{tabular}{|l} 
Variant \\
Exclusion \\
Matrix
\end{tabular} & $\begin{array}{l}\text { (Otto and Hölttä-Otto, } \\
\text { 2007),(Andersen, } \\
\text { Hadzic, and Pisinger, } \\
\text { 2010), (Schuh, } \\
\text { Rudolf, and Riesener, } \\
\text { 2014) }\end{array}$ & $\sqrt{4}$ & \begin{tabular}{|l|} 
Commonality \\
targets in \\
employee \\
review
\end{tabular} & \begin{tabular}{|l|} 
(Boas et al., 2013), \\
(Meyer and Maltin, \\
$2010)$
\end{tabular} & 1,4 \\
\hline \multirow{3}{*}{$\begin{array}{l}0 \\
\mathbf{r} \\
\mathrm{g} \\
\mathrm{a} \\
\mathrm{n} \\
\mathrm{i} \\
\mathrm{z}\end{array}$} & $\begin{array}{l}\text { Commonality } \\
\text { ownership }\end{array}$ & $\begin{array}{l}\text { (Boas et al., 2013), } \\
\text { (Cragg } \\
\text { Greenbaum, 2002) }\end{array}$ & $\begin{array}{lr}5, & 9 \\
11, & 12\end{array}$ & \begin{tabular}{|lr} 
Profit r and \\
Loss Scope
\end{tabular} & $\begin{array}{l}\text { (Kim and Chhajed, } \\
2000)\end{array}$ & $\begin{array}{ll}1, & 2, \\
11 & \end{array}$ \\
\hline & $\begin{array}{l}\text { Module } \\
\text { control } \\
\text { governance } \\
\text { board } \\
\end{array}$ & $\begin{array}{|lr|}\text { (Cloud, } & \text { 1998), } \\
\text { (Brunninge, } & \\
\text { Nordqvist, } & \text { and } \\
\text { Wiklund, 2007) } & \\
\end{array}$ & $\sqrt{4,5}$ & $\begin{array}{l}\text { Lead } \\
\text { development } \\
\text { project }\end{array}$ & $\begin{array}{l}\text { (Pasche, Persson, and } \\
\text { Löfsten, } \\
(\text { Lenfle, 2007) }\end{array}$ & $\begin{array}{l}4,5,7 \\
9, \quad 10 \\
11\end{array}$ \\
\hline & \begin{tabular}{|l} 
Design \\
review \\
participants
\end{tabular} & $\begin{array}{l}\text { (Otto and Hölttä-Otto, } \\
\text { 2007), (Lau, Mak, } \\
\text { and Lu, 2003), } \\
\text { (Ulrich and Eppinger, } \\
\text { 2004) }\end{array}$ & $\begin{array}{l}1,2,3 \\
5,8\end{array}$ & \begin{tabular}{|l|}
$\begin{array}{l}\text { Variant } \\
\text { ordering } \\
\text { volume }\end{array}$ \\
\end{tabular} & (Jans et al., 2008) & $\begin{array}{ll}4, & 9, \\
11 & \end{array}$ \\
\hline \multirow[t]{2}{*}{$\mathbf{i}$} & & & & $\begin{array}{l}\text { Contract } \\
\text { strategy }\end{array}$ & $\begin{array}{|lr|}\text { Farrell and Simpson, } \\
2010), \\
\text { (Skitmore } \\
\text { Pemberton, } \\
\text { (Foss, 2000) }\end{array}$ & 3,7 \\
\hline & & & & $\begin{array}{l}\text { Cross- } \\
\text { functional } \\
\text { savings } \\
\text { targets }\end{array}$ & $\begin{array}{|lr|}\text { Pinto } & \text { and Pinto, } \\
1990), & \text { (Cameron, } \\
2011), & \text { (Webber, } \\
2002) & \end{array}$ & $\begin{array}{l}3,5,7 \\
10\end{array}$ \\
\hline
\end{tabular}

A short description of each of the management levers identified follows. We use the following terminology in the descriptions below:

Variants: Discrete products offered for sale, which participate in a platform Common part: A part shared in multiple places within one variant or across variants.

Module: A part type with a specific function, of which there may be multiple module variants. For example, we might have three alternators, identified as three module variants.

\section{Control Management Levers}

Scope of investment evaluation - Which variants are considered in the scope of the investment for the platform? Our observation is that early variants tend to spend up the majority of the investment, while later variants tend to receive the majority of the benefits of commonality. If only the first variant is in scope, the savings which accrue to later variants will not be present in the analysis of the internal rate of return (IRR) or net present value (NPV). 
Example from Case 9 (Commercial Aircraft): One engine was funded and designed and is utilized for all Product Family $\mathrm{C}$ variants in scope, with thrust being selectable. Use of the larger engine on a smaller aircraft results in lower operating costs due to the longer on-wing time enabled by the less demanding operating scenario. It was asserted that developing different engines for varieties of products in Family $\mathrm{C}$ would have required greater investments.

Development cost allocation - How are the development costs allocated to variants? If later variants receive common parts, what allocation rule (volume, profit, fixed share, etc.) will determine their contribution?

Example from Case 7 (Military Aircraft): The program was originally funded jointly from a single program office, i.e. there was no explicit division of development cost among the three aircraft variants.

Mandatory co-investment in parts - Are users of common parts responsible for contributing to the initial development cost? Mandatory co-investment is a policy of forcing all users of common parts to contribute, according to some development cost allocation. Mandatory coinvestment is often used at the part-level, across programs that do not consider themselves to be a cohesive "platform".

Example from Case 4 (Automotive): Historically, a new infotainment system would have been paid for by the first platform to use it (the scope of investment evaluation was Platform 1). Under new guidelines, any new vehicles coming to market in the next two years that were planning to use the infotainment system were required to contribute investment upfront.

Production cost allocation - Many commonality benefits arise during production. Economies of scale, quality benefits, and learning curves are but three examples. How will the capital equipment investments and overhead allocations be distributed among variants?

Example from Case 9 (Commercial Aircraft): A history of single product production combined with a long lifecycle industry created a single product company culture. Tooling costs are borne explicitly by the first product, and offered for free to the later products.

Transparent cost supply chain - What information will be made available about the costs of variety for supplied parts? Understanding what variety is internally costly to deliver represents an important input to divergence decisions, and yet the contractual barrier can make this a difficult determination.

Example from Case 4 (Automotive): The manufacturer noted that variety in the coloring of the carpets was inexpensive, but variety in shape of carpets was expensive. Suppliers had disclosed in the contracting phase that changing the coloring required only changing the dye bottles, while changing the size required buying a new die at substantial cost.

Variant Impact Matrix - When a change is proposed to a common part, the Variant Impact Matrix requires that the development, production, and operations costs be evaluated with respect 
to each variant. This provides visibility, and prevents one variant from diverging for a cost savings that has increased cost consequences for the platform as a whole.

Example from Case 7 (Military Aircraft): The manufacturer used a template called the "Eight Square Template" to identify the impact to each of the downstream product variants. This template had to be completed from the perspective of each downstream variant, and was reviewed for technical merit as well as overall program benefit.

Commonality metrics - Is a shared parts metric tracked over time? Are targets set for this metric? This measurement represents a key state variable for a platform.

Example from Case 6 (Helicopter): The ratio of common parts to total parts was tracked over time as one of the key performance parameters for the program. An initial goal was set, and the resulting program came relatively close to achieving that goal.

Tagging intended common parts - When common parts are designed on the first variant, are they identified as intended common to later variants? Common parts often require additional investment - if this investment is not noted, later variants may erroneously assume they can modify any and all parts.

Example from Case 5 (Automotive): A SUV team began developing a vehicle, and a truck program was scheduled to start two years later. The SUV development program explicitly identified certain parts intended for sharing with the truck. Although the truck program was aware of the intention to reuse these parts, many were designed anew by the truck program.

Architecture control strategy - During the design phase, are architectural standards (such as fixed interfaces, standardized wheelbase, etc.) identified and communicated? In their absence, common parts may not be adopted on later variants due to geometric constraints or changes in interfaces.

Example from Case 2 (Heavy Equipment): Two products were explicitly design to the same component voltage levels, so that components could be interchanged between them.

Variant Exclusion Matrix - Does the platform track which module variants can be used with which other module variants?

Example from Case 4 (Automotive): Three engine mounts and three engines were designed. The question was: can each engine use any engine mount, or are there constraints? The Variant Exclusion Matrix tracked these relationships so module owners can identify feasible combinations.

Commonality Ownership - Are decisions on common parts made by an actor who has visibility to both the investments and the savings that will occur? When no one in the organization has ownership of common parts, each variant makes decisions in their own interests, potentially reducing the level of investment possible from combined resources. 
Example from Case 5 (Automotive): A senior decision-maker was appointed with oversight of two programs. The goals set for the two program managers did not include benefits accrued by the other program, but the senior decision-maker had explicit commonality ownership, i.e. the perspective and the willingness to invest in the first program and see benefits only in the second program.

Module control governance board - A module control board reviews modules change requests and has the authority to approve or deny changes to existing module variants or to allow the creation of new module variants.

Example from Case 5 (Automotive): Components were broken into three tiers: "true commodities", "configurable commodities", and "unique parts". The first was subject to strong governance practices including a board, the second was subject to a lower tier authorization, and the third was not centrally governed.

Design review participants - Which functional and product stakeholders are present at design reviews? Do functional stakeholders (such as procurement or manufacturing) play an active role in setting constraints for the platform?

Example from Case 8 (Business Aircraft): Design reviews include not only engineers and the R\&D department, but participants reflect a cross-functional team of key stakeholders, including sales, procurement, manufacturing, maintenance, and industrialization departments.

\section{Incentive Management Levers}

New part introduction cost - Is there a financial charge for creating new parts? This functions as a disincentive to create new parts and an incentive to reuse existing parts. This charge can be set by estimating indirect activities from part creation, or can be set as a financial incentive independent of activity costs.

Example from Case 2 (Heavy Equipment): An organizational rule was implemented that added a new part creation cost of $\$ 7000$ to any new part creation request, in addition to the immediate design effort, in attempt to recognize the lifecycle cost of maintaining parts in inventory.

Taxing non-common parts - Are programs charged fees for non-common parts? Similar to new part introduction cost, this lever acts on all unique parts (which could be reused from past programs but used only once on the current program) rather than on new parts only.

Example from Case 4 (Automotive): The manufacturer implemented a punitive tax on noncommon parts after a design consolidation. A commonality owner collected the tax from subscribing product lines. This effort was successful in incentivizing additional commonality.

Transfer pricing - Are variants allowed to sell modules to other variants? In contrast to production cost allocation, transfer pricing allows variants to build margin into the charge for a module. 
Example from Case 2 (Heavy Equipment): The firm had separate production facilities for engines and final assembly, and it set engine transfer prices at the engine factory in order to enable the engine factory to track its finances more easily and avoid setting a firm-wide overhead rate. In effect, engines functioned as a PnL.

Corporate investment pool for common parts - Is there funding available from outside the platform, which is designated for common parts only? This incentive acts as a subsidy for common parts, and is often coupled with new technology introduction. In some cases, corporate funding is used to advance a future program funding, before its $\mathrm{PnL}$ is available to charge therefore this is sometimes coupled to development cost allocation.

Example from Case 4 (Automotive): A small pool of funding was available from corporate, that programs could use to fund additional development costs associated with common parts. The intention was to "subsidize" common parts, recognizing that they often were more expensive to design than unique parts for the originating program.

Shaming: Part proliferation studies - Has an analysis been conducted to identify all historical module variants? If this analysis reveals similar module variants with irrelevant differences (from a customer perspective), it can be communicated as a warning to part designers, or as a consolidation opportunity in the supply chain.

Example from Case 1 (Vehicles): Motivated by steel price increases and by parts proliferation, the manufacturer identified 12,000 different non-complex components, of which only 3,000 were in current production. Consolidation after the part proliferation studies resulted in $\$ 5 \mathrm{M} /$ year savings.

Reuse databases - Is there a database of parts indexed by module names or part function? These databases represent the hypothesis that engineers aren't reusing parts because they can't find historical parts, or because engineers perceive it is less time consuming to design anew than to reuse.

Example from Case 12 (Semiconductor): A reuse database was developed to help engineers identify potential reuse candidates across product lines. Although reuse improved, reuse remained stronger between generations of the same product line than across product lines.

Commonality targets in employee reviews - Is variable compensation linked to a commonality metric for the platform manager, for variant managers, or for engineers? This is a relatively strong incentive that places importance on choosing wise targets that represent a balance between product differentiation and cost savings.

Example from Case 4 (Automotive): Target parts reuse from previous generations was set as one of the goals for platform managers, which in turn was linked to promotion cases and variable compensation. 
Profit and Loss Scope - Does the common part or platform span multiple PnLs? There are natural incentives for sharing within a PnL, whereas sharing across PnLs can require explicit development cost allocations or transfer pricing.

Example from Case 11 (Printing Presses): Two product lines saw a reduction in commonality relative to the original plan because one had more stringent requirements and the other made design choices to accommodate existing confirmed orders. There was no mandate for sharing and there were no incentives from the PnL structure to encourage commonality, so each product line made design choices in its own best interest.

Lead development project - Is the platform a separate initiative or is it a part of the lead variant's scope? Carving the platform out as a separate initiative relieves pressures associated with market timing and the integration of common and unique content into a single product, but may isolate the platform from market signals.

Example from Case 10 (Commercial Satellites): The development strategy shifted from a platform supporting an entire product family (run as a separate initiative) to meeting the needs of one specific customer (part of the lead variant's scope). In the end, there was a lead project, and later products were sequentially adapted from this lead.

Variant ordering by volume - If variants are not developed in parallel, in what order are they developed? If bulk purchase benefits are intended, there is a natural incentive for later variants to be common with the lead variant if the largest volume variant is ordered first. By contrast, the largest volume variant may be the most likely to break, if the volumes of others are small.

Example from Case 5 (Automotive): A truck (largest volume) and an SUV (low volume) were developed, but with the SUV development leading. At the start of the truck development, many intended common parts were redesigned as unique to the truck, because the truck was able to garner similar prices in the supply chain using its volume, thus contributing to divergence. Meanwhile, the SUV part prices went up substantially when the truck volume did not materialize on its purchasing contracts.

Contract strategy - Are the benefits of commonality explicitly called out in supplier contracts for common parts? Do contracts include development cost payments intended to cover multiple module variants? Does the firm centralize purchasing of common components with a single supplier for a bulk purchase benefit, or does it use the volume of common parts to compete two or more suppliers against each other?

Example from Case 3 (Rail): The company paid for the non-recurring development of a component at a supplier, which was expected to be modified for use on two subsequent variants. For the second and third module variants, the supplier contested that the original payment was only for the original module variants. The contract language had not clearly identified scope of payment.

Cross-functional savings targets - Do the representatives of each function impacted by commonality have platform savings targets? Do they have a direct or indirect reporting 
relationship to the platform manager or to the variant managers? This lever relates to the degree of support versus ownership of financial savings that the functional representatives take on.

Example from Case 3 (Rail): An engineering manager attempted to design for manufacturing and testing, but manufacturing was unaware of plans to complete partial builds and store them in inventory - manufacturing did not have financial targets linked explicitly to the platform.

Together, these management levers constitute potential actions that can be taken to shape behaviors around common components. For example, in an organization with concerns about largest-volume variants making commonality decisions without regard to other variants, managers could adjust the development cost allocation in order to award more weight to the concerns of profitable but low volume variants. We find several familiar themes echoed in these management levers: control vs. coordination, centralized vs. decentralized firm structure, taxation as a disincentive, and challenges searching in large corporate contexts. We do not suggest that the levers described here should be interpreted as best practice or that firms implement all of them. In each case, special care should be taken in deciding which management levers to use and to which extent, and, chosen carefully, they can calibrate the balance of these tensions.

It is important to mention that not all management levers are successful in preventing divergence. In general, most study participants spoke about the use of the levers as a means to help them achieve sharing and financial goals. In Case 6, after the evaluation of a product's sales and performance, it was concluded that commonality divergence would be beneficial and that it should not be prevented. This case provided an example of how failure to allow beneficial divergence to occur can result in less successful product variants. Several companies placed an emphasis on determining the exact extent of the benefit. The unacknowledged downside of this was that some benefits, which were difficult to estimate, were assumed to be zero. The cases often demonstrated that failure to plan for a benefit indicated it was less likely to arise. Therefore, some sort of blanket design guidance has to be available. The existence of heavy commonality premiums in design (Cameron, 2011) shows that if left to their own devices, there will often be one variant that stands to pay more and benefit less from commonality than others. If both control and funding are distributed mostly to variants, the platform is left with fewer available management levers, and the platform manager will play more of a coordination role than a control role. Several cases expressed the desire to choose only commonality that benefits all variants. While in theory this should lead to strong equilibrium, the reality of commonality investments is that one variant will often bear the cost. Unless the investing variant has a mechanism to recover its investment from other variants, it will fail to invest.

\section{Conclusions}

This paper provides a list of management levers to control and incentivize commonality, which may help in preventing platform divergence. This list summarizes a broad literature review and is extended to include management levers found during case studies.

These levers are built from an exploratory mixed-methods case study research strategy. The case context was restricted to 12 cases in capital-intensive manufacturing industries with slow clockspeeds to enable comparisons. Both commonality and divergence have been evidenced in a much broader context and, as such, the results presented are conceptually 
extensible but further research will be required in order to establish the salience of this issue in other industries, such as fast clockspeed environments (Beckman and Sinha, 2005). This list offers managers choices about how to shape behaviors around commonality decision points. In particular, it suggests levers to employ to mitigate conflicts between product customization, optimization, and cost control which cause divergence.

Platform managers face significant challenges in calibrating programs to feasible commonality levels. Decisions to either retain commonality or pursue individualized solutions should be dependent on a platform perspective, rather than a variant mentality. Evaluating changes with respect to only one variant will not accurately reflect the platform optimum for cost. Similarly, estimating only the incremental effort while ignoring erosion of future benefits will lead to a less than optimum solution.

Commonality benefits are difficult to evaluate because they require assessment of complex problem spaces, with many variables that occur in ambiguity and uncertainty conditions. We do not state comparisons of the efficacy of the levers, as they might differ substantially across contexts. An assumption of the framing of this issue is that management levers are discrete actions that can be taken - however, in some contexts they made be necessarily linked to other actions, and therefore not discrete actions. Similarly, we assume that actions are taken uniformly across an organization - this research did not examine whether, for example, new part introduction costs were levied across all departments or all programs. This study and the suggested management levers are limited to the context of the industries in which they were used.

Future work is required to explore the degree of coupling between these levers, and their correlation to benefit achievement. Further, exploration of management levers in fast clockspeed industries, such as electronics manufacturing, might yield interesting insights into the applicability of levers relative to the decision horizon.

\section{References}

Alavi, M., \& Leidner, D. E. (2001). Review: Knowledge management and knowledge management systems: Conceptual foundations and research issues. MIS Quarterly, 25(1), 107-136.

Alptekinoglu, A., \& Corbett, C. J. (2008). Mass customization vs. mass production: Variety and price competition. Manufacturing Service Operations Management, 10(2), 204217.

Andersen, H. R., Hadzic, T., \& Pisinger, D. (2010). Interactive Cost Configuration over Decision Diagrams. J. Artif. Int. Res., 37(1), 99-140. 
Arvey, R. D., \& Ivancevich, J. M. (1980). Punishment in Organizations: A Review, Propositions, and Research Suggestions. The Academy of Management Review, 5(1), 123. http://doi.org/10.2307/257812

Baker, K. R., Magazine, M. J., \& Nuttle, H. L. W. (1986, August 1). The Effect of Commonality on Safety Stock in a Simple Inventory Model [research-article]. Retrieved March 25, 2014, from http://pubsonline.informs.org/doi/citedby/10.1287/mnsc.32.8.982

Beckman, S., \& Sinha, K. K. (2005). Conducting academic research with an industry focus: Production and operations management in the high tech industry. Production and Operations Management, 14(2), 115-124.

Ben-Arieh, D., \& Qian, L. (2003). Activity-based cost management for design and development stage. International Journal of Production Economics, 83(2), 169-183.

Blecker, T., \& Abdelkafi, N. (2007). The Development of a Component Commonality Metric for Mass Customization. IEEE Transactions on Engineering Management, 54(1), 7085. http://doi.org/10.1109/TEM.2006.889068

Boas, R. (2008). Commonality in Complex Product Families: Implications of Divergence and Lifecycle Offsets (Ph.D. Thesis). MIT ESD.

Boas, R., Cameron, B. G., \& Crawley, E. F. (2013). Divergence and lifecycle offsets in product families with commonality. Systems Engineering, 16(2), 175-192.

Boyer, K. K., \& Verma, R. (2010). Operations \& supply chain management for the 21st century. Mason, Ohio: South-Western/Cengage Learning.

Bradley, J. R., \& Guerrero, H. H. (2008). Product Design for Life-Cycle Mismatch. Production and Operations Management, 17(5), 497-512.

Bremner, R. (1999). Cutting Edge Platforms. Financial Times Automotive World, 30-38. 
Brunninge, O., Nordqvist, M., \& Wiklund, J. (2007). Corporate Governance and Strategic Change in SMEs: The Effects of Ownership, Board Composition and Top Management Teams. Small Business Economics, 29(3), 295-308.

Burgess, T. F., McKee, D., \& Kidd, C. (2005). Configuration management in the aerospace industry: a review of industry practice. International Journal of Operations \& Production Management, 25(3), 290-301.

Cameron, B. G. (2011). Costing commonality: evaluating the impact of platform divergence on internal investment returns (Thesis). Massachusetts Institute of Technology.

Cameron, B. G., \& Crawley, E. F. (2012). Costing commonality: Investigating the impact of platform divergence. In 2012 IEEE Aerospace Conference (pp. 1-9).

Cameron, B. G., \& Crawley, E. F. (2013). Advances in Product Family and Product Platform Design - Methods \& Applications. Springer.

Cescon, F. (2002). Short-term perceptions, corporate governance and the management of $R$ \& D in Italian companies. Journal of Management and Governance, 6(3), 255-270.

Chern, C.-C., \& Yang, I.-C. (2011). A heuristic master planning algorithm for supply chains that consider substitutions and commonalities. Expert Systems with Applications, 38(12), 14918-14934. http://doi.org/10.1016/j.eswa.2011.05.055

Cloud, P. A. (1998). - Change control board. In P. A. Cloud (Ed.), Engineering Procedures Handbook (pp. 323-326). Westwood, NJ: William Andrew Publishing.

Costa, J. M. H., Rozenfeld, H., Amaral, C. S. T., Marcacinit, R. M., \& Rezende, S. O. (2013). Systematization of Recurrent New Product Development Management Problems. Engineering Management Journal, 25(1), 19-34. 
Cragg, W., \& Greenbaum, A. (2002). Reasoning about Responsibilities: Mining Company Managers on What Stakeholders are Owed. Journal of Business Ethics, 39(3), 319335. http://doi.org/10.1023/A:1016523113429

Creswell, J. W. (2013). Research Design: Qualitative, Quantitative, and Mixed Methods Approaches (Fourth Edition edition). Thousand Oaks: SAGE Publications, Inc.

Cusumano, M. A., \& Nobeoka, K. (1998). Thinking beyond lean: how multi-project management is transforming product development at Toyota and other companies. Free Pr.

Desai, P., Kekre, S., Radhakrishnan, S., \& Srinivasan, K. (2001). Product differentiation and commonality in design: Balancing revenue and cost drivers. Management Science, $37-51$.

Dong, M., \& Chen, F. F. (2005). The impacts of component commonality on integrated supply chain network performance: a state and resource-based simulation study. The International Journal of Advanced Manufacturing Technology, 27(3), 397-406.

Drstvensek, I., Ficko, M., \& Balic, J. (2004). Relational database as a cogitative part of an intelligent manufacturing system. Journal of Materials Processing Technology, 157158, 114-122. http://doi.org/10.1016/j.jmatprotec.2004.09.021

Du, X., Jiao, J., \& Tseng, M. M. (2001). Architecture of product family: fundamentals and methodology. Concurrent Engineering, 9(4), 309-325.

Eisenhardt, K. M. (1989). Building Theories from Case Study Research. The Academy of Management Review, 14(4), 532-550. http://doi.org/10.2307/258557 
Engwall, M., \& Jerbrant, A. (2003). The resource allocation syndrome: the prime challenge of multi-project management? International Journal of Project Management, 21(6), 403-409. http://doi.org/10.1016/S0263-7863(02)00113-8

Eschenbach, T., Lewis, N., Henrie, M., Baker, I. Elisha, \& Hariman, J. C. (2007). Real Options and Real Engineering Projects. Engineering Management Journal, 19(4), 11-19.

Farrell, R. S., \& Simpson, T. W. (2010). Improving cost effectiveness in an existing product line using component product platforms1. International Journal of Production Research, 48(11), 3299-3317. http://doi.org/10.1080/00207540802620753

Fine, C. H. (1998). Clockspeed: Winning industry control in the age of temporary advantage. Basic Books.

Fisher, M. L., Jain, A., \& MacDuffie, J. P. (1995). Strategies for product variety: lessons from the auto industry. Oxford University Press, New York.

Fisher, M., Ramdas, K., \& Ulrich, K. (1999). Component Sharing in the Management of Product Variety: A Study of Automotive Braking Systems. Manage. Sci., 45(3), 297315. http://doi.org/10.1287/mnsc.45.3.297

Foss, N. J. (2000). The Theory of the Firm: Critical Perspectives on Business and Management. Taylor \& Francis.

Fujita, K. (2002). Product variety optimization under modular architecture. Computer-Aided Design, 34(12), 953-965.

Geiger, T. S., \& Dilts, D. M. (1996). Automated design-to-cost: integrating costing into the design decision. Computer-Aided Design, 28(6-7), 423-438.

Greene, J. C., Caracelli, V. J., \& Graham, W. F. (1989). Toward a conceptual framework for mixed-method evaluation designs. Educational Evaluation and Policy Analysis, 11(3). 
Harris, L. R., \& Brown, G. T. L. (2010). Mixing Interview and Questionnaire Methods: Practical Problems in Aligning Data. Practical Assessment, Research \& Evaluation, 15(1).

Hauser, J. (2001). Metrics thermostat. Journal of Product Innovation Management, 18(3), 134-153.

Hölttä-Otto, K., Tang, V., \& Otto, K. (2008). Analyzing module commonality for platform design using dendrograms. Research in Engineering Design, 19(2-3), 127-141.

Hoppmann, J., Rebentisch, E., Dombrowski, U., \& Thimo Zahn. (2011). A Framework for Organizing Lean Product Development. Engineering Management Journal, 23(1), 315.

Jans, R., Degraeve, Z., \& Schepens, L. (2008). Analysis of an industrial component commonality problem. European Journal of Operational Research, 186(2), 801-811.

Johnson, M. D., \& Kirchain, R. (2010). Developing and Assessing Commonality Metrics for Product Families: A Process-Based Cost-Modeling Approach. IEEE Transactions on Engineering Management, 57(4), 634-648.

Jose, A., \& Tollenaere, M. (2005). Modular and platform methods for product family design: literature analysis. Journal of Intelligent Manufacturing, 16(3), 371-390.

Keating, C. B., Padilla, J. J., \& Adams, K. (2008). System of Systems Engineering Requirements: Challenges and Guidelines. Engineering Management Journal, 20(4), 24-31.

Khosrowpour, M. (1996). Information Technology Management and Organizational Innovations: Proceedings of the 1996 Information Resources Management Association International Conference, Washington. Idea Group Inc (IGI). 
Kim, K., \& Chhajed, D. (2000). Commonality in product design: Cost saving, valuation change and cannibalization. European Journal of Operational Research, 125(3), 602621.

Kogut, B., \& Kulatilaka, N. (1999). Options thinking and platform investments: Investing in opportunity. The Internationalization of the Firm, 278.

Krishnan, T. V., Bass, F. M., \& Jain, D. C. (1999). Optimal pricing strategy for new products. Management Science, 1650-1663.

Krishnan, V., \& Gupta, S. (2001). Appropriateness and Impact of Platform-Based Product Development. Management Science, 47(1), 52-68.

Krishnan, V., \& Loch, C. H. (2005). A retrospective look at production and operations management articles on new product development. Production and Operations Management, 14(4), 433-441.

Labro, E. (2004). The cost effects of component commonality: a literature review through a management-accounting lens. Manufacturing \& Service Operations Management, 6(4), 358.

Lam, J. (2014). Enterprise Risk Management: From Incentives to Controls. John Wiley \& Sons.

Landaeta, R. E. (2008). Evaluating Benefits and Challenges of Knowledge Transfer Across Projects. Engineering Management Journal, 20(1), 29-38.

Lau, H. Y. K., Mak, K. L., \& Lu, M. T. H. (2003). A virtual design platform for interactive product design and visualization. Journal of Materials Processing Technology, 139(13), 402-407. http://doi.org/10.1016/S0924-0136(03)00510-7 
MacDuffie, J. P., Sethuraman, K., \& Fisher, M. L. (1996). Product variety and manufacturing performance: evidence from the international automotive assembly plant study. Management Science, 350-369.

Ma, S., Wang, W., \& Liu, L. (2002). Commonality and postponement in multistage assembly systems. European Journal of Operational Research, 142(3), 523-538.

Meyer, J. P., \& Maltin, E. R. (2010). Employee commitment and well-being: A critical review, theoretical framework and research agenda. Journal of Vocational Behavior, 77(2), 323-337. http://doi.org/10.1016/j.jvb.2010.04.007

Meyer, M. H. (1997). Revitalize your product lines through continuous platform renewal. Research Technology Management, 40(2), 17.

Meyer, M., \& Lehnerd, A. (1997). The Power of Product Platforms. New York: Free Press.

Mirchandani, P., \& Mishra, A. K. (2002). COMPONENT COMMONALITY: MODELS WITH PRODUCT-SPECIFIC SERVICE CONSTRAINTS*. Production and Operations Management, 11(2), 199-215.

Muffatto, M., \& Panizzolo, R. (1996). Innovation and product development strategies in the Italian motorcycle industry. Journal of Product Innovation Management, 13(4), 348361.

Nepal, B. P., Yadav, O. P., \& Solanki, R. (2011). Improving the NPD Process by Applying Lean Principles: A Case Study. Engineering Management Journal, 23(1), 52-68.

Ngai, E. W. T., Cheng, T. C. E., Lai, K., Chai, P. Y. F., Choi, Y. S., \& Sin, R. K. Y. (2007). Development of an RFID-based Traceability System: Experiences and Lessons Learned from an Aircraft Engineering Company. Production and Operations Management, 16(5), 554-568. 
Nobelius, D., \& Sundgren, N. (2002). Managerial issues in parts sharing among product development projects: a case study. Journal of Engineering and Technology Management, 19(1), 59-73.

Otto, K., \& Hölttä-Otto, K. (2007). A multi-criteria assessment tool for screening preliminary product platform concepts. Journal of Intelligent Manufacturing, 18(1), 59-75.

Pasche, M., Persson, M., \& Löfsten, H. (2011). Effects of platforms on new product development projects. International Journal of Operations \& Production Management, 31(11), 1144-1163. http://doi.org/10.1108/01443571111178475

Phaal, R., \& Paul J. Palmer. (2010). Technology Management--Structuring the Strategic Dialogue. Engineering Management Journal, 22(1), 64-74.

Pinto, M. B., \& Pinto, J. K. (1990). Project team communication and cross-functional cooperation in new program development. Journal of Product Innovation Management, 7(3), 200-212. http://doi.org/10.1016/0737-6782(90)90004-X

Ramdas, K. (2003). Managing product variety: An integrative review and research directions. Production and Operations Management, 12(1), 79-101.

Ramdas, K., \& Randall, T. (2008). Does Component Sharing Help or Hurt Reliability? An Empirical Study in the Automotive Industry. Management Science, 54(5), 922-938.

Robertson, D., \& Ulrich, K. (1998). Planning for product platforms. Sloan Management Review, 39, 19-32.

Rungtusanatham, M. J., \& Salvador, F. (2008). From mass production to mass customization: Hindrance factors, structural inertia, and transition hazard. Production and Operations Management, 17(3), 385-396. 
Schuh, G., Rudolf, S., \& Riesener, M. (2014). Similarity-based Product Configuration. Procedia CIRP, 17, 290-295. http://doi.org/10.1016/j.procir.2014.01.056

Sered, Y., \& Reich, Y. (2006). Standardization and modularization driven by minimizing overall process effort. Computer-Aided Design, 38(5), 405-416.

Shi, J. (Junmin), \& Zhao, Y. (2014). Component commonality under no-holdback allocation rules. Operations Research Letters, 42(6-7), 409-413.

Simons, R. (2013). Levers of Control: How Managers Use Innovative Control Systems to Drive Strategic Renewal. Harvard Business Press.

Simpson, T. W. (2005). Product platform design and customization: Status and promise. AI EDAM, 18(01), 3-20.

Simsarian Webber, S. (2002). Leadership and trust facilitating cross-functional team success. Journal of Management Development, 21(3), 201-214.

Skitmore, M., \& Pemberton, J. (1994). A Multivariate Approach to Construction Contract Bidding Mark-up Strategies. The Journal of the Operational Research Society, 45(11), 1263. http://doi.org/10.2307/2583854

Sutton, R. I. (1997). The Virtues of Closet Qualitative Research. Organization Science, 8(1), $97-106$.

Sylvain Lenfle, S. B. M.-J. (2007). New Product development in a platform-driven organization : Towards platform lifecycle management. HAL, Post-Print.

Tatikonda, M. V. (1999). An empirical study of platform and derivative product development projects. Journal of Product Innovation Management, 16(1), 3-26.

Triantis, A. J. (2000). Real options and corporate risk management. Journal of Applied Corporate Finance, 13(2), 64-73. 
Ulrich, K. (1995). The role of product architecture in the manufacturing firm. Research Policy, 24(3), 419-440. http://doi.org/10.1016/0048-7333(94)00775-3

Ulrich, K., Randall, T., Fisher, M., \& Reibstein, D. (1998). Managing product variety. Product Variety Management, 177-205.

Ulrich, K. T., \& Eppinger, S. D. (2004). Product design and development. McGraw-Hill/Irwin.

Vidal, C. J., \& Goetschalckx, M. (2001). A global supply chain model with transfer pricing and transportation cost allocation. European Journal of Operational Research, 129(1), 134-158.

Ward, J., Zhang, B., Jain, S., Fry, C., Olavson, T., Mishal, H., ... others. (2010). HP transforms product portfolio management with operations research. Interfaces, 40(1), 17-32.

Yin, R. K. (1981). The case study crisis: Some answers. Administrative Science Quarterly, 26(1), 58-65.

Zimmerman, J. (2005). Accounting for Decision Making and Control (5th ed.). McGraw-Hill Education.

\section{Biographies}

\section{Bruce G. Cameron}

Dr. Bruce Cameron is the founder of Technology Strategy Partners (TSP), a consulting firm, and the Director of the System Architecture Lab at MIT. Dr. Cameron received his undergraduate degree from the University of Toronto, and graduate degrees from MIT

As a Partner at TSP, Dr. Cameron consults on system architecture, product development, technology strategy, and investment evaluation. He has worked with 60 Fortune 500 firms in high tech, aerospace, transportation, and consumer goods.

\section{Edward F. Crawley}

Dr. Edward Crawley is the Ford Professor of Aeronautics and Astronautics at MIT. He received an S.B. and an S.M. in Aeronautics and Astronautics and an Sc.D. in aerospace structures, all from MIT. Prof. Crawley is the Past President of the Skolkovo Institute of 
Science and Technology (Skoltech) in Moscow, Russia,

Dr. Crawley has founded a number of companies, including ACX, a product development and manufacturing firm and Dataxu, a company in Internet advertising placement.

\title{
Jakub Kwapisz
}

Dr. Jakub Kwapisz is a Global Product Manager at Autoneum, a producer of vehicle acoustic systems. Dr Kwapisz received his Masters of Engineering from Politechnika Warszawska, and his Ph.D. from Instituto Superior Tecnico in Portugal. Dr. Kwapisz previously worked at Alstom Transport, where he was responsible for identifying commonality opportunities across products.

\begin{abstract}
Alicia McNeill
Alicia McNeill is a Consultant with Technology Strategy Partners, where she has worked closely with clients in medical devices, aerospace, and oil and gas. Previously, she was responsible for budgeting and corporate finance at Vertex Pharmaceuticals. Earlier in her career, she worked at Raytheon in program management, system engineering, and business development. She holds an M.S. in System Design and Management from MIT and a B.S. in Operations Research \& Industrial Engineering from Cornell University.
\end{abstract}

